\title{
Research on Reading Teaching of University English Based on CBI Yang Peng ${ }^{1}{ }^{*}{ }^{\text {Liu Weixiang }}{ }^{1}$ \\ ${ }^{1}$ Department of Fundamental English, Nanchang University College of Science and Technology, Nanchang, Jiangxi, China \\ * Corresponding Author: Yang Peng
}

Keywords: English reading teaching, CBI, application

\begin{abstract}
Content-based Instruction (CBI) is a teaching approach that combines the language teaching with the content teaching and has an effect on promoting learning efficiency. This paper firstly gives the current situation of university English reading teaching, then expounds the advantages of CBI in university English reading teaching, and finally elaborates the instruction practices of university English reading teaching reforms based on CBI to provide some references for the university English teachers.
\end{abstract}

\section{Current Situation of University English Reading Teaching}

Reading is an important means that modern human access the information and knowledge. The cultivation of English reading ability plays an important role in the cultivation of students in colleges and universities. However, at present, mostly university English reading courses mainly bear the English communicative functions and it can't bear the responsibility of thinking ability. The things that the input and output establish language forms and limits of the reading practice, coupled with different grade reading curriculum content and logical cohesion, cannot satisfy the cognitive needs of students. After entering the university, the students learn process relying more on memory, imitation, recitation and retelling, rarely engaged in complex rich challenging thinking activity, so their thinking ability in long-term depressed state. It is not possible to get enough training and development. In the past, the thinking ability of English major students than other liberal arts students seems to be weaker. It shows that their own understanding and analysis of the problem, rather than the analysis of the problem of teaching methods to students. So this long-term step by step approach which can only train students' basic skills gives the students' enthusiasm of learning. It also obstructs the thinking ability development in a certain extent.

\section{Advantages of CBI in University English Reading Teaching}

The core idea of CBI (Content-based Instruction) is to abandon the past learning language method, and learning the language in a subject or a certain subject content of teaching so that students can improve the language ability in learning the subject at the same time.

CBI method is conducive to the cultivation of good reading habits. The purpose of English reading course is to cultivate students' reading comprehension ability and to improve their reading speed. The CBI teaching mode emphasizes the content as the basis on two aspects. The students' reading materials with wide range of subjects, rich in content to provide a large amount of language input. Through the language knowledge and cultural background knowledge training, it can stimulate interest, expand one's scope of knowledge, cultivate their good reading habits and improve the reading speed. At the same time, students are familiar with a variety of browsers and master strong reading skills in the process of completing the task according to the needs to access the Internet.

CBI method is conducive to broaden the horizons of students. Traditional reading class is about two hours per week. Teachers should instruct the basic knowledge and complete the provisions of teaching content. Students should practice the language form and content. The traditional method will inevitably subject to the limitations of materials, time and so on many aspects of the conditions, in addition to the outside of the text and several supplementary exercises very hard and read a few 
other content. The CBI teaching mode emphasizes the extracurricular reading to reading classroom supplement and promotion, the theme content effectively extended to extra-curricular, students in the topics of interest actively looking for topic and reading materials, active thinking. Students can strengthen the various reading skills, accumulate gradually consolidate existing knowledge, and construct the new knowledge structure in the teaching process based on CBI.

CBI method is conducive to changing the role of teachers. In the teaching based on CBI, teachers shift the roles from the narrator in the traditional method to the organizers of class activities, the mentor of the reading skills and the supervisors of reading tasks. Students change their roles from the receivers to accepters. The acquire knowledge and master the methods of learning in the active thinking activities. In the traditional reading teaching class, the teacher's power tends to be too large. Teachers not only determine the contents of the students reading, and the classroom is often too much, so that students can only passively listen, take notes, students learning initiative and initiative is severely restricted. In order to change the unreasonable phenomenon of teachers roles in traditional reading teaching mode, English reading teaching based on the CBI changes the roles of teachers and students in class. CBI makes the teachers become the students' interest excitation, classroom activities organizers and reading task supervisor. The teachers have flexible teaching methods and modern teaching means to fully mobilize students' initiative.

\section{Reforms Practices of University English Reading Teaching Based on CBI}

Teaching Objectives. The purpose of the reading course should be located in the ability to cultivate students' reading comprehension, but also to cultivate students' knowledge of the width and the depth of thinking. It should be to cultivate the professional talents with practical ability of English. This kind of talented person not only needs a solid knowledge and skills, but also requires a wide range of knowledge background and a good ability to think. Take the study of business administration major as an example. Project learning is to meet a series of specific objectives and a number of related works in a certain period of time. It is a kind of teaching mode with students as the center, through a long-term task, to promote students in the process of implementation of the task of inquiry and empirical, so as to obtain knowledge and skills. Compared with the traditional classroom teaching, project learning provides students with the opportunity to develop integrated skills, and puts forward higher requirements for students' autonomous learning ability. Project learning concept, then let the students in the learning content at the same time, the development of students' comprehensive skills. Reading teaching based on CBI method helps teachers to set the more correct teaching objectives.

Teaching Content. Teaching content is the key to the teaching. The core element of CBI is the language material must be true and reliable, and must be prepared by the native speakers. This point can be done as long as the English teachers pay attention to the teaching materials choice. Due to the publication year and selection of materials, textbooks often have a certain lag, and due to the limitations of space, the traditional reading teaching is difficult to really let the students read a large number of extensive readings. CBI theme mode, teachers should first base on the theme of student selection and topic to help students choose the relevant supplementary materials. In the selection of supplementary materials should be preferred by the English speaking countries, the author writing, for the countries of common English readers and non-English learners in passages for students to read, such as news stories from English speaking countries published newspapers and magazines on the excerpt, special reports, classic or modern fiction excerpts and movies, television script excerpt. This kind of article authentic language can encourage students to make full use of the reading skills and reading level gain substantial increase. CBI English reading course for learners to provide meaningful language learning environment, the architecture based on classic literature of human experience platform, the use of literature in the classroom is a can make learners as input a complete person effective method for learning provides the expression of their views, affective response and great opportunity. In the curriculum efforts to classical short of modern and contemporary Chinese literary works, tilt, and difficulty is not larger, more new words, length of the works, to enable students to unable to read the contents of the interest, so that teachers can only talk about story 
background and outline, cannot take the aesthetic interpretation of works into account. At the same time, supplementary materials choice should take different genres, short length and moderate difficulty into account. Teachers should give students a certain reading task, encourage them to expand their reading in the chosen subject and learn from the ocean of books or internet.

Teaching Models. There are four commonly used teaching models in CBI. They are respectively the theme-based approach, sheltered-content courses adjunct courses and courses of language for special purposes. In the practical application, all the models have advantages and disadvantages. Teachers should the suitable models according to the teaching content. The theme of teaching material is selected from the target language of the original theme and topic. The selected topics, topics should be based on student needs, should be able to arouse the interest of students. Theme mode is intended to obtain new information by using language as the medium, while the process of acquiring new information and improving the level of language. Around the topic, the theme, to carry out comprehensive training, and gradually deepening. To cultivate students' independent learning ability by using various teaching methods, such as list, picture, film and television, simulation, etc. Subject model mainly by foreign language teachers to undertake the task of teaching, can be responsible for language teachers. The course model of teaching materials from the target language of all kinds of professional courses, the difficulty should be in line with the language level of students and professional ability to accept. Students are required to acquire the knowledge of the subject rather than the language knowledge, which is intended to acquire linguistic competence through comprehensible input. Auxiliary mode is a kind of mode that offers professional and language courses at the same time. Language courses for the professional class service, requires students to use language knowledge to master the professional content. The auxiliary model is jointly undertaken by both professional teachers and foreign language teachers, and is responsible for the teaching of specialized courses and supporting language courses. Special model of teaching content and a particular industry or professional has a close relationship. The choice of teaching model should be considered first. Only the teaching model which can achieve the teaching purpose should be chosen.

Teaching Relationship. CBI teaching approaches emphasize the students' center ideas. The relationship between teaching and learning is no longer the traditional relationship. Teachers in the classroom verbatim to explain and students in the classroom verbatim copy the context. The relationship between teachers and students likes the relationship between strangers. Under the frame of CBI teaching, the teacher uses the teaching method and the teaching method of the problem. Teachers can use appropriate teaching methods to guide students to take the initiative to understand the writing background and the author's writing style, so that the design of the learners to ease the anxiety, to help learners to enter the natural. The teachers carefully design a series of discussion questions, guide students to read, in-depth work, pay attention to understanding and appreciation, they contains profound thought research, guide students to learn from the cultural, history, philosophy, psychology, and multi angle to interpret works, forming critical thinking. After reading the discussion time to group discussion, summed up the form of speech to make class report. Therefore, teachers should encourage learners to actively participate in the question and answer, group discussion, thematic debate and other speculative activities, and guide learners to combine emotional experience to express personal views. Teachers should encourage and guide students in extra-curricular using network tool again deep thinking, independent inquiry, collection, collation of information, will obtain the knowledge of digestion and absorption, forming their teachers to view the developing discussion in class. After class, they are topics of interest to submit papers for the job. This can arouse students' participation awareness and mobilize students' subjective initiative, and cultivate students' independent thinking, independent analysis of scientific research ability. In teaching to cultivate students' inquiry learning method, is conducive to extensive stimulate students' sense of participation. It can improve their autonomous learning ability and cultivate scientific way of thinking and research methods to explore a new model of English reading teaching and the new situation. Teachers and students promote each other, forming a harmonious relationship between them in the university English reading teaching based on CBI. 


\section{Conclusion}

The concept of modern English reading teaching emphasizes on applying the multi-teaching method to stimulate students' interest in learning and creates the good learning environment. The university English reading teaching based on CBI adapts to the student needs and provides authentic language material. It can effectively stimulate students' interest in learning, enrich the teaching content and improve the relationship between teachers and students.

\section{References}

[1] Liu Yang, A Study of English Reading Based on CBI Teaching Concept. J., Foreign Language Research, 2015(3):135-138.

[2] Gao Zhiguo, Wang Yaping, CBI and Its Implications for the Teaching of Business Reading and Business Writing, Journal of Gansu Lianhe University (Social Sciences), 2013(7):108-111.

[3] Cui Xiuhong, Pan Yanhui, CBI-based Reform of Reading Course Teaching for English Majors, J., Journal of Zhejiang University of Technology (Social Science) , 2012(9):351-355.

[4] Zheng Yueli, Gao Zhihuai, A Study on the Reform Strategies of the English Reading Textbook-based on CBI, J., English on Campus, 2014(3):45-47. 